\title{
Study of Polyolefin Gel in Organic Solvents I. Structure of Isotactic Polypropylene Gel in Organic Solvents
}

\author{
Hideomi Matsuda, Tadashi Inoue, Masaru OKABE, \\ and Takeshi UKAJI* \\ Department of Chemical Engineering, Faculty of Textile Science, \\ Shinshu University, 3-15-1, Tokida, Ueda, Nagano 386, Japan \\ *Department of Chemical Process Engineering, Faculty of Engineering, \\ Ikutoku Technical University, 1030, Shimo-ogino, \\ Atsugi, Kanagawa 243-02, Japan
}

(Received July 3, 1986)

\begin{abstract}
Sol-gel transition and the structure of isotactic polypropylene (itPP) gels formed from toluene and $o$-xylene solutions were studied. Weight-average molecular weight range of samples used is from $25.8 \times 10^{4}$ to $50.1 \times 10^{4}$. A thermo-reversible gel was formed from a semi-dilute solution on cooling. Gel-melting temperature $T_{\mathrm{m}}^{\mathrm{g}}$ was measured and its dependency on polymer concentration as well as molecular weight was investigated. $T_{\mathrm{m}}^{\mathrm{g}}$ increased gradually with increasing polymer concentration and obeyed Eldridge-Ferry's type of plot: the reciprocal absolute gelmelting temperature $1 / T_{\mathrm{m}}^{\mathrm{g}}$ had a linear relationship to the logarithm of volume fraction of polymer, while molecular weight dependency of $T_{\mathrm{m}}^{\mathrm{g}}$ was little. In a gel, many spherulites were observed, the spherulites were bound with crystalline ties, and a three-dimensional network structure was observed. In this crystalline network, a polymer solution was confined. It is concluded that the formation of spherulites and crystalline ties is conducive to gelation.
\end{abstract}

KEY WORDS Sol-Gel Transition / Thermo-Reversible Gel / Polypropylene / Isotactic Polypropylene / Morphology / Structure of Gel / GelMelting Temperature / Spherulite /

It is a well-known phenomenon that some crystalline copolymers or crystalline polymers form gels from dilute or semi-dilute solutions on cooling, and studies on the crystallization process, network formation, and gel formation have been reported by many workers. ${ }^{1-18}$ Sol-gel transition of crystalline polymers is thermally reversible, and the structure of crystalline gel is essentially different from a gel whose network is formed by covalently crosslinking amorphous chains, wherein the network is thermally stable. ${ }^{19}$ Recently, the industrial application of such a crystalline polymer gel, particularly of ultrahigh molecular weight polyethylene or polypropylene, has become a topic because the gel exhibits excellent spinnability, and fibers or films obtained by drawing of the gel show high modulus and strength. ${ }^{20-25}$ However, the structure of the gel as well as the mechanism of gelation has not been satisfactorily clarified.

When a polymer solution converts to a gel, crosslinking junction points should be formed in the gel. Takahashi and co-workers have pointed out for this problem, through experiments of $\mathrm{X}$-ray diffraction and gel-melting temperature of crystalline polymer gel such as poly(vinyl chloride) or ethylene-vinyl acetate copolymer, that junction points are polymer crystallites, and then they have derived a thermodynamic theory for melting of crystallites. ${ }^{1,5,26}$ Recently, Mandelkern and coworkers have investigated thermo-reversible gelation and crystallization of homopolymers 
and copolymers of ethylene in toluene, $p$ xylene, and decalin, and reported that gelation takes place as a consequence of crystallization and a three-dimensional network is formed where primary molecules are bound together, or connected, by crystallites. ${ }^{19}$

In this study, we report the sol-gel transition of isotactic polypropylene (itPP) in organic solvents and investigate the structure of gels using an ordinary microscope, a polarizing microscope, and a scanning electron microscope. We obtained a somewhat different network structure wherein, existed many spherulites in contact with each other, being bound with crystalline ties. This indicates that these spherulites and crystalline ties form a three-dimensional network structure. Furthermore, gel-melting temperature is measured and its dependency on polymer concentration as well as molecular weight is examined.

\section{EXPERIMENTAL}

\section{Materials}

Five samples of unfractionated itPP supplied by Showa Denko Co. were used. Typical physical properties of samples are listed in Table I. Weight-average molecular weight $\bar{M}_{w}$ ranged from $25.8 \times 10^{4}$ (PP-6) to $50.1 \times$ $10^{4}$ (PP-3).

For purification, polymers were dissolved in xylene at its boiling point under a reflux and then precipitated in an excess of cooled methanol with stirring. After washing with methanol, the sample was filtered and sufficiently dried under reduced pressure at $70^{\circ} \mathrm{C}$. Toluene and $o$-xylene used as solvents were obtained from Kanto Chemical Co. and purified according to the usual method before use.

\section{Method of Gel Formation and Measurement of Gel-Melting Temperature}

Measurements of gel-melting temperature were carried out by the falling-ball method,
Table I. Typical physical properties of isotactic polypropylenes ${ }^{a}$

\begin{tabular}{|c|c|c|c|c|}
\hline \multirow{2}{*}{ Sample } & Density & \multirow{2}{*}{$\begin{array}{c}\bar{M}_{w} \times 10^{-4} \\
(\mathrm{GPC})\end{array}$} & \multirow{2}{*}{$\frac{\alpha}{\%}$} & \multirow{2}{*}{$\frac{T_{\mathrm{m}}^{0}}{{ }^{\circ} \mathrm{C}}$} \\
\hline & $\mathrm{g} \mathrm{cm}^{-3}$ & & & \\
\hline PP-1 & 0.900 & 38.6 & 34.2 & 157.8 \\
\hline PP-2 & 0.901 & 28.0 & 35.6 & 157.9 \\
\hline PP-3 & 0.899 & 50.1 & 26.6 & 157.3 \\
\hline PP-5 & 0.900 & 31.8 & 35.3 & 158.3 \\
\hline PP-6 & 0.901 & 25.8 & 35.2 & 158.0 \\
\hline
\end{tabular}

a $\bar{M}_{w}$, weight-average molecular weight determined by GPC; $\alpha$, degree of crystallinity determined by DSC; $T_{\mathrm{m}}^{0}$, melting temperature determined by DSC.

which was pioneered by Takahashi and coworkers, ${ }^{26}$ using a glass tube of $c a .35 \mathrm{~cm}$ height and $1 \mathrm{~cm}$ diameter. The dependence of gel-melting temperature on the size of a steel ball was examined by a preliminary experiment, and that of $2 \mathrm{~mm}$ diameter ( $\mathrm{ca}$. $30 \mathrm{mg}$ ) was selected.

Gels were prepared as follows: an appropriate amount of sample and solvent along with a steel ball were put into a glass tube and sealed. After the steel ball was held by means of a magnet at the upper part of the glass tube, the polymer was dissolved at about $130^{\circ} \mathrm{C}$ in a glycerin bath. Finally, the glass tube was placed in a thermobath kept at $30^{\circ} \mathrm{C}$ for $16 \mathrm{~h}$ to make a gel.

The steel ball was then carefully carried to the surface of gel layer by a magnet and the system was heated at a rate of about $6^{\circ} \mathrm{C} \mathrm{h}^{-1}$, while the height of the steel ball from a reference level was recorded by a cathetometer at a selected temperature. At first, the steel ball on the gel stayed at a constant level. When the gel melted, or converted to a sol, it began to fall downward. An example of measurements is illustrated in Figure 1. The temperature at which the horizontal and vertical straight lines intersected was defined as the gel-melting temperature. The measurements were repeated several times at each concentration: the reproducibility of the data was as good as $\pm 1{ }^{\circ} \mathrm{C}$. The average was used for subsequent discus- 


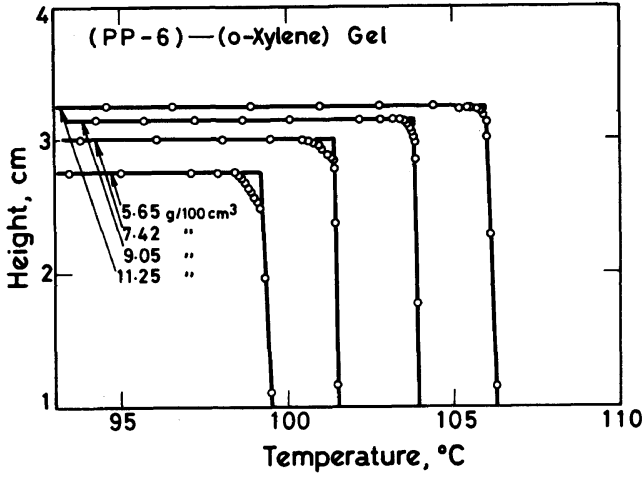

Figure 1. Examples of measurements of gel-melting temperature by the falling-ball method.

sion.

\section{Observation of Gel by Scanning Electron Microscope (SEM)}

The sample preparation for SEM measurements. was carried out as follows: After a gel was lyophilized, the specimen was coated with a thin layer of gold by the evaporation technique. The morphology was observed and photographed using an Akashi Model ALPHA-10 scanning electron microscope.

\section{Observation of Gel by Polarizing Microscope}

Observation of crystallites formed in a gel was also carried out using an Olympus Model BHA-P polarizing microscope. The gel was carefully placed on a slide glass and a cover glass was put on the gel. Then, crystallites were observed with crossed nicols.

\section{RESULTS AND DISCUSSION}

The critical concentration to form a gel in toluene and $o$-xylene found was about $5 \mathrm{~g} /$ $100 \mathrm{~cm}^{3}$, the same as the itPP-decalin and itPP-tetralin systems reported in the previous study. ${ }^{27}$ All gels exhibited considerable turbidity. In the lower concentration region, the solution did not convert to the gel according to the method of gel formation described in the Experimental Section, but crystalline phase

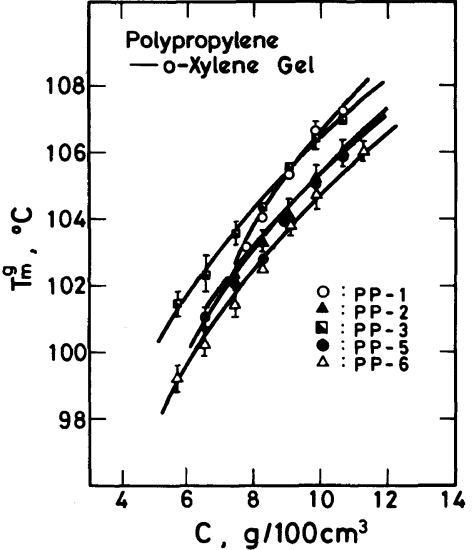

Figure 2. Relation between gel-melting temperature $T_{\mathrm{m}}^{\mathrm{g}}\left({ }^{\circ} \mathrm{C}\right)$ and polymer concentration $C\left(\mathrm{~g} / 100 \mathrm{~cm}^{3}\right)$ for itPP-o-xylene gel.

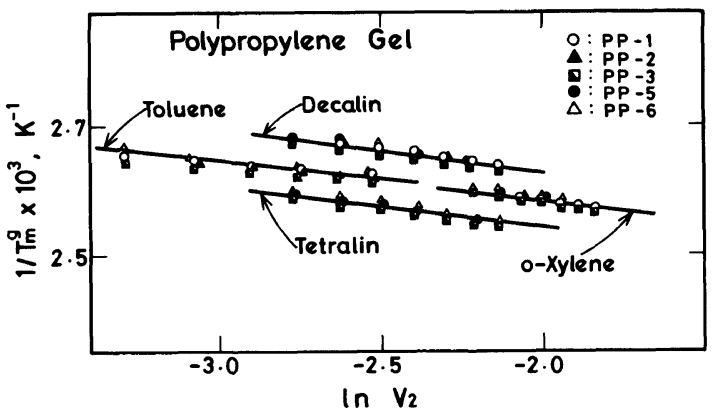

Figure 3. Relation between the reciprocal absolute gelmelting temperature $1 / T_{\mathrm{m}}^{\mathrm{g}}\left(\mathrm{K}^{-1}\right)$ and logarithm of the volume fraction of itPP in a gel $\ln V_{2}$ : Eldridge-Ferry's type plot.

separation took place on cooling.

Concentration and Molecular Weight Dependencies of Gel-Melting Temperature

Examples of the relation between observed gel-melting temperature $T_{\mathrm{m}}^{\mathrm{g}}\left({ }^{\circ} \mathrm{C}\right)$ and polymer concentration $C\left(\mathrm{~g} / 100 \mathrm{~cm}^{3}\right)$ in $o$-xylene are shown in Figure 2. For each sample, the gelmelting temperature increased very slowly with increasing polymer concentration, and this tendency was similar to those observed in itPP-toluene system and also to those for polyethylene gels reported previously. ${ }^{28-30}$ The difference of $T_{\mathrm{m}}^{\mathrm{g}}$ between the samples of 

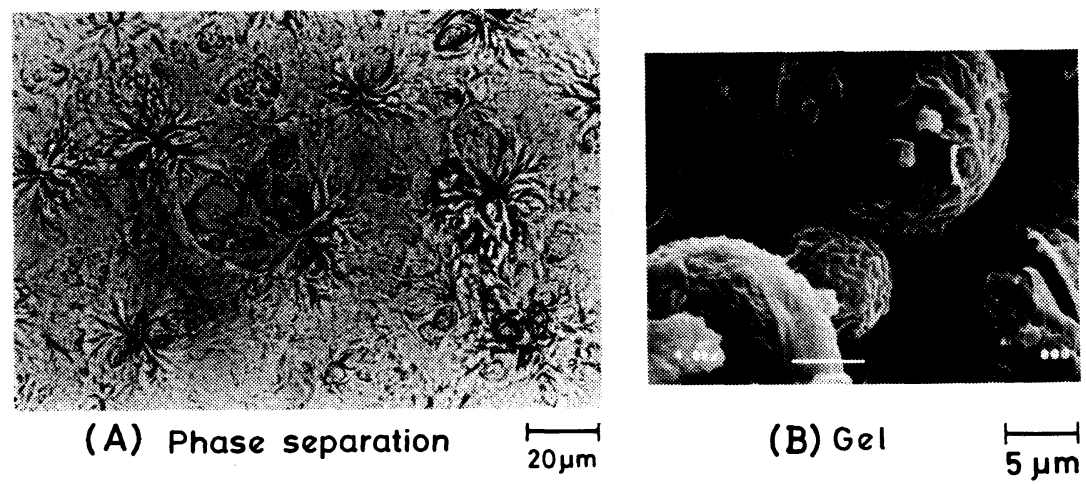

Figure 4. Photographs of sheaf-like crystals (A) taken by an ordinary microscope and spherulites (B) taken by SEM. (A): PP-5-o-xylene system at a concentration of $0.5 \mathrm{~g} / 100 \mathrm{~cm}^{3}$. (B): PP-5-decalin system at a concentration of $8 \mathrm{~g} / 100 \mathrm{~cm}^{3}$.

different molecular weight was within about $2-3^{\circ} \mathrm{C}$ and thus very small.

Eldridge and Ferry ${ }^{31}$ proposed empirically the following relationship between gel-melting temperature and polymer concentration:

$$
\ln V_{2}=\text { const. }+\Delta H_{\mathrm{m}} / R T_{\mathrm{m}}^{\mathrm{g}}
$$

where $V_{2}$ is the volume fraction of polymer and $\Delta H_{\mathrm{m}}$ is the heat absorbed on formation of one mole of junction points. According to eq 1 , a plot of $\ln V_{2}$ vs. $1 / T_{\mathrm{m}}^{\mathrm{g}}\left(\mathrm{K}^{-1}\right)$ should yield a straight line. The plot has been made and illustrated in Figure 3 together with the results of $\mathrm{PP}$-tetralin and $\mathrm{PP}$-decalin systems. ${ }^{27}$ Excellent straight lines were obtained and the present experimental results for gelmelting temperature-concentration relation obeyed eq 1. On the other hand, for each solvent, plots have been reduced to an almost straight line without regard to the difference in molecular weight. Thus, the dependence of gel-melting temperature on molecular weight is not significant.

\section{Structure of Isotactic Polypropylene Gel}

As mentioned above, the itPP solution did not convert to a gel in its dilute solution, and many sheaf-like crystals were observed in a concentration range less than about $1 \mathrm{~g} /$ $100 \mathrm{~cm}^{3}$ as shown in Figure 4(A). On the contrary, typical spherulites were observed in a gel as shown in Figure 4(B). It is considered, therefore, that the sheaf-like crystal is an early growth process of spherulite and, by and by, becomes a spherulite with increasing polymer concentration. An example of a photograph of crystallites formed in a gel is also shown in Figure 5, which was taken by a polarizing microscope with crossed nicols after evaporating the solvent slightly. In this photograph, the Maltese cross and an outline of the spherulite can be observed together.

It was found above that the gel definitely included many spherulites. So, the dependence of the size of spherulite on polymer concentration was investigated. Measurements of size were carried out as follows: A precipitate or gel formed in a glass tube was placed on a slide glass and sufficiently dried under reduced pressure at $70^{\circ} \mathrm{C}$. Then, the spherulites were photographed using an ordinary microscope and their diameters were measured. In Figure 6 , the relation between the polymer concentration and the spherulite diameter for PP- 1 in toluene and $o$-xylene are shown. At each concentration, there was a distribution of spherulite size. Even in a concentration region of about $1-5 \mathrm{~g} / 100 \mathrm{~cm}^{3}$, where a gel was not formed and polymer precipitated from solution, relatively small spherulites with about 
$10-30 \mu \mathrm{m}$ diameter were observed. The diameter and number of spherulite increased gradually with increasing polymer concentration, and the diameter of spherulites obtained from gels was approximately 30$40 \mu \mathrm{m}$. A similar tendency was obtained for

(PP-2)-o-Xylene gel

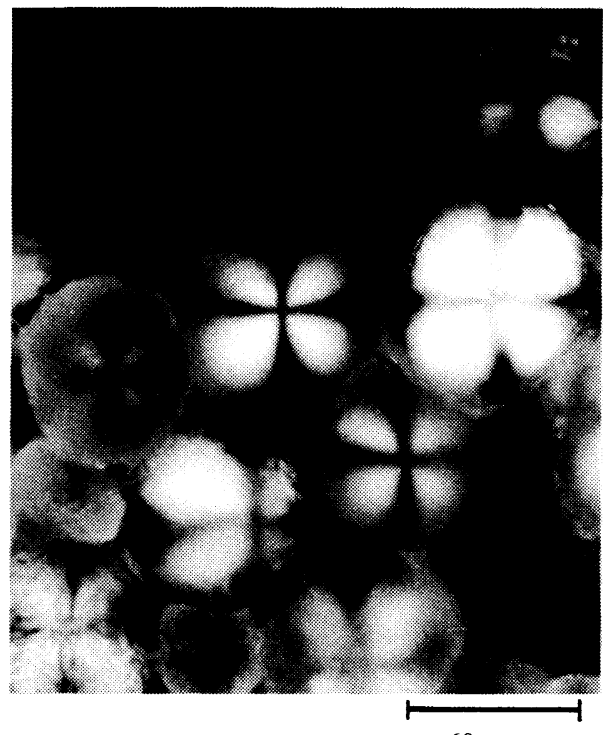

$60 \mu \mathrm{m}$

Figure 5. Photograph of spherulites in PP-2-o-xylene gel taken by a polarizing microscope with crossed nicols: concentration, $11 \mathrm{~g} / 100 \mathrm{~cm}^{3}$; molecular weight of PP-2, $\bar{M}_{w}=28.0 \times 10^{4}$. other samples.

Photographs of crystallites in gels taken by an ordinary microscope and SEM are shown in Figures 7 and 8. As seen in these photographs, many spherulites are in contact with each other and crystalline ties bind the spherulites. In order to form a gel from a solution, therefore, it is necessary that the spherulites grow to an appropriate size so as to contact each other, the spherulites to be bound by crystalline ties, and the polymer solution to be confined by these crystallites.

The existence of intercrystalline links between spherulites of polyethylene crystallized from the melt has already been observed by Keith and co-workers. ${ }^{32}$ In this study, we also showed such intercrystalline links (crystalline ties) between itPP spherulites in a gel. In the case of a gel, it is considered that the spher-

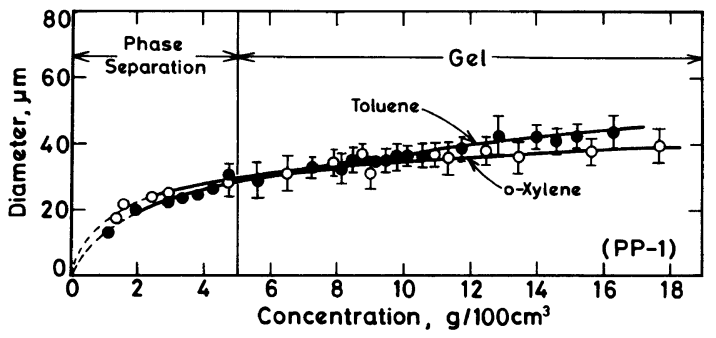

Figure 6. Relation between spherulite diameter of PP1 and polymer concentration in toluene and $o$-xylene.
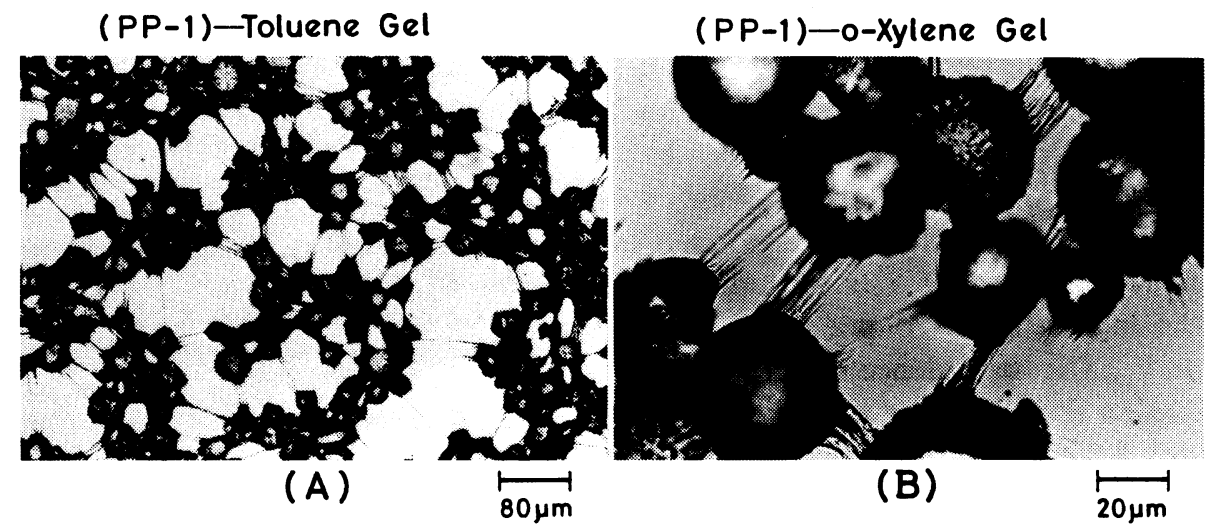

Figure 7. Examples of spherulites and crystalline ties-among spherulites: (A), PP-1-toluene gel at a concentration of $7 \mathrm{~g} / 100 \mathrm{~cm}^{3}$; (B), PP-1-o-xylene gel at a concentration of $11 \mathrm{~g} / 100 \mathrm{~cm}^{3}$. Both photographs were taken by an ordinary microscope. 

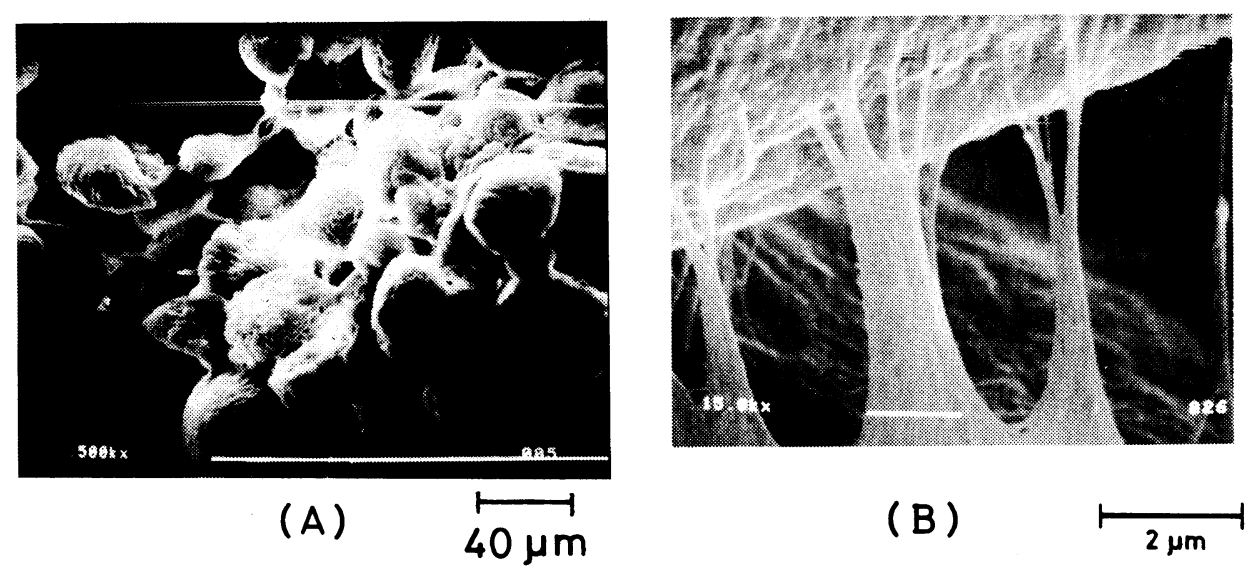

Figure 8. Examples of spherulites and crystalline ties taken by SEM: (A), PP-2-o-xylene gel at a concentration of $12 \mathrm{~g} / 100 \mathrm{~cm}^{3}$; (B), PP-3-O-xylene gel at a concentration of $10 \mathrm{~g} / 100 \mathrm{~cm}^{3}$.

ulites and crystalline ties form a three-dimensional network structure. In other words, the formation of spherulites and crystalline ties leads to gelation.

\section{CONCLUSIONS}

The following results were obtained for the structure of itPP gel in organic solvents:

1. An itPP in toluene and $o$-xylene converts to a gel from its semi-dilute solution on cooling, and the gel converts to a solution on heating. The sol-gel transition is thermoreversible. The critical concentration for gel formation is about $5 \mathrm{~g} / 100 \mathrm{~cm}^{3}$.

2. The gel-melting temperature depends on polymer concentration. The concentration dependency of gel-melting temperature can be well represented by the Eldridge-Ferry's type of plot: the reciprocal absolute gel-melting temperature $1 / T_{\mathrm{m}}^{\mathrm{g}}$ has a linear relationship to the logarithm of volume fraction of polymer $\ln V_{2}$. The dependence of gel-melting temperature on the molecular weight is little.

3. Many spherulites in contact with each other and the spherulites bound with crystalline ties are observed in the gel, which indicates that these spherulites and crystalline ties form a three-dimensional network structure of a gel, and the polymer solution is confined in this network.

Acknowledgement. The authors wish to express their sincere appreciation to $\mathrm{Mr}$. Yoshihiro Motegi of the Ohita Laboratory, Showa Denko Co. for supplying and characterizing the itPP samples.

\section{REFERENCES}

1. A. Takahashi, T. Nakamura, and I. Kagawa, Polym. J., 3, 207 (1972).

2. B. Wunderlich and P. Sullivan, J. Polym. Sci., 61, 195 (1962).

3. D. C. Bassett, A. Keller, and S. Mitsuhashi, J. Polym. Sci., A, 1, 763 (1963).

4. A. J. Pennings, J. M. A. A. van der Mark, and H. C. Booij, Kolloid Z.-Z. Polym., 236, 99 (1970).

5. A. Takahashi, Polym. J., 4, 379 (1973).

6. A. Takahashi and S. Hiramitsu, Polym. J., 6, 103 (1974).

7. P. J. Lemstra and G. Challa, J. Polym. Sci., Polym. Phys. Ed., 13, 1809 (1975).

8. M. Girolamo, A. Keller, K. Miyasaka, and N. Overbergh, J. Polym. Sci., Polym. Phys. Ed., 14, 39 (1976).

9. A. J. Pennings, J. Polym. Sci., Polym. Symp., 59, 55 (1977).

10. E. D. T. Atkins, D. H. Isaac, A. Keller, and K. Miyasaka, J. Polym. Sci., Polym. Phys. Ed., 15, 211 (1977).

11. R. Benson, J. Maxfield, D. E. Axelson, and L. Mandelkern, J. Polym. Sci., Polym. Phys. Ed., 16, 


\section{Structure of Polypropylene Gel}

1583 (1978)

12. A. Keller, Polymer, 20, 1371 (1979).

13. A. Takahashi, T. Kawaharada, and T. Kato, Polym. J., 11, 671 (1979).

14. P. J. Barham, M. J. Hill, and A. Keller, Colloid Polym. Sci., 258, 899 (1980).

15. P. Smith, P. J. Lemstra, and H. C. Booij, J. Polym. Sci., Polym. Phys. Ed., 19, 877 (1981).

16. C. O. Edwards and L. Mandelkern, J. Polym. Sci., Polym. Lett. Ed., 20, 355 (1982).

17. T. Tanigami, K. En, K. Yamaura, and $\mathrm{S}$. Matsuzawa, Polym. J., 18, 31 (1986).

18. T. Tanigami, K. Yamaura, S. Matsuzawa, and K. Miyasaka, Polym. J., 18, 35 (1986).

19. R. C. Domszy, R. Alamo, C. O. Edwards, and L. Mandelkern, Macromolecules, 19, 310 (1986).

20. P. Smith and P. J. Lemstra, J. Mater. Sci., 15, 505 (1980).

21. P. Smith, P. J. Lemstra, J. P. L. Pijpers, and A. M. Kiel, Colloid Polym. Sci., 259, 1070 (1981).

22. C. G. Cannon, Polymer, 23, 1123 (1982).
23. A. Peguy and R. St. J. Manley, Polym. Commun., 25, 39 (1984).

24. M. Matsuo, C. Sawatari, M. Iida, and M. Yoneda, Polym. J., 17, 1197 (1985).

25. S. Mitsuhashi and M. Iguchi, Kobunshi, 34, 94 (1985).

26. A. Takahashi, M. Sakai, and T. Kato, Polym. J., 12, 335 (1980).

27. M. Okabe and H. Matsuda, Kobunshi Ronbunshu, 42, 397 (1985).

28. H. Matsuda, M. Imaizumi, H. Fujimatsu, S. Kuroiwa, and M. Okabe, Polym. J., 16, 151 (1984).

29. M. Okabe, M. Isayama, and H. Matsuda, Polym. J., 17, 369 (1985).

30. M. Okabe, M. Isayama, and H. Matsuda, J. Appl. Polym. Sci., 30, 4735 (1985).

31. J. E. Eldridge and J. D. Ferry, J. Phys. Chem., 58, 992 (1954).

32. H. D. Keith, F. J. Padden, Jr., and R. G. Vadimsky, J. Polym. Sci., A-2, 4, 267 (1966). 